\title{
Does Individual Interest Still Predict Achievement in Science and Technology When Controlling for Self-Concept? A Longitudinal Study Conducted in Canadian Schools
}

\author{
Patrice Potvin ${ }^{1 *}$, Abdelkrim Hasni ${ }^{2}$, Jean-Philippe Ayotte-Beaudet ${ }^{2}$, Ousmane Sy ${ }^{3}$ \\ 1 University of Quebec in Montreal, CANADA \\ 2 University of Sherbrooke, CANADA \\ ${ }^{3}$ University of Quebec at Trois-Rivières, CANADA
}

Received 3 June 2020 - Accepted 25 September 2020

\begin{abstract}
This cross-lagged longitudinal study was conducted with 862 seventh and eighth graders (secondary school) in the province of Québec (Canada) to study the effects of two important perceptual variables (self-concept and individual interest) on achievement, as well as reciprocal relations between all these constructs. Considering the results obtained previously in mathematics education, it was designed to test if the same inter-variable dynamics could be recorded in science and technology. The data was gathered at 10 time points (four perceptual; six report cards [school reports]) and analyzed using Mplus. Most fit indexes were acceptable and revealed a predictive solution that supports the hypothesis that interest does not appear to play any direct role in achievement, but that self-concept does. Recommendations for research that tests individual interest are formulated as well as suggestions for educational practice.
\end{abstract}

Keywords: achievement, interest, longitudinal, science and technology, self-concept

\section{CONTEXT}

\section{Perceptual Constructs and Achievement}

In certain disciplines, like mathematics and science, student's achievement and perceptions, like the interest they manifest for these fields, have attracted a lot of attention from policy-makers and teachers worried about the observed decline in interest and the relative decrease in university enrolment, particularly in science and engineering. Their concern also extends to scientific culture levels, as they suspect negative social, economic and environmental consequences if science is rejected (OECD, 2008).

Indeed, it is generally taken for granted that when a student performs well in a certain subject, his/her achievement will then nourish his/her pride, and thus his/her self-concept and possibly also his/her interest in this subject. However, and maybe more surprisingly, the opposite is also often assumed. Indeed, if someone believes that he/she is good at something, it is reasonable to presume that he/she will be more inclined to make sustained efforts, and thus perform better at it (Honicke \& Broadbent, 2016). But also, it is often implicitly accepted that the more someone is interested in something, the more he/she will be engaged in learning new things about it (Patall, Vasquez, Steingut, Trimble, \& Pituch, 2016), and thus this should reflect in subsequent performances.

This hypothesis, sometimes called the "standard hypothesis" of interest (Rotgans \& Schmidt, 2017), posits that there could be direct and causal links between interest and achievement. In short, perceptual constructs are not considered to be neutral in the educational landscape, and many research and innovation efforts have concentrated on their positive development, hoping that such improvements can extend and positively affect learning, understanding, and eventually achievement. 


\section{Contribution to the literature}

- This study addresses the important question of achievement vs. perceptual variables in science education.

- The study contributes to the existing literature by using a rather robust and infrequently used longitudinal panel design (Structural equation modelling). It also contributes by extending to the context of science and technology education a conclusion that has recently gained support in mathematics education.

- Unlike many previous research efforts, it controls for many confounding variables and tests many participants.

- The results bring support to the hypothesis that self-concept is a strong predictor of achievement (and conversely); while it challenges the widespread assumption that individual interest is.

- The study also provides insights on possible ways to better define and measure individual interest in the context of science learning, and it provides a reflection on the role of evaluation in science classes.

\section{Correlations between Perceptual Constructs; and with Achievement}

Many initially encouraging correlational studies using questionnaires have over the years recorded statistically significant positive relations between perceptual constructs and achievement (Cavas, 2011; George, 2006; Reid \& Skryabina, 2002; Schiefele, Krapp, \& Winteler, 1992), as well as between perceptual constructs themselves (Lent, Larkin, \& Brown, 1989). However, such correlations between perceptual constructs (usually closely related to a particular knowledge object) might not be as surprising, since perceptions are not always completely mutually exclusive, neither in questionnaires nor in participants understanding of them. For example, interest and selfconcept both have strong affective components, which cannot be easily differentiated.

Even reciprocal effects between, for example, interest and self-concept, are to be expected and are indeed recorded (Lent, Brown, \& Hackett, 1994), sometimes even in longitudinal designs (Denissen, Zarrett, \& Eccles, 2007). However, they also appear rather weak, and the net directionality of their dominance (A toward B or conversely) is sometimes unclear (Ganley \& Lubienski, 2016).

However, the relation with and the effects on achievement of perceptual constructs might be more educationally interesting than their reciprocal influences, especially for practitioners, since achievement is presumed to reveal learning, which is the ultimate goal of most academic activity.

\section{What about the Relationship Between Self-Concept and Achievement?}

Along with prior achievement, gender and sociocultural variables, self-concept may be one of the most studied variables in the prediction of academic success. The general idea refers to "collections of beliefs that individuals hold about themselves" (Leflot, Onghena, \& Colpin, 2010), but sometimes also has more specific forms that can focus, for instance, on what one is capable (or not) of accomplishing (self-efficacy), or even sometimes on specific tasks, like success expectancy (Nuutila, Tuominen, Tapola, Vainikainen, \& Niemivirta, 2018). Self-concept is often assessed by comparing oneself to one's peers, their capabilities, or to the relative effort provided to obtain equivalent results.

It is therefore unsurprising that achievement and grades predict self-concept. Often praised by adults, academic performance most certainly serves as a basis for self-evaluation. Self-concept is a natural and sometimes expected product of grades. And indeed, we have known for a long time that grades and self-concept are fairly correlated (Brookover, Thomas, \& Paterson, 1964). Such a correlation survives research efforts that strive to control other confounding or covariables. Larson et al., for example, controlled for gender, interest and effort and still recorded a significant relation of selfconcept with physics and chemistry learning (Larson, Stephen, Bonitz, \& Wu, 2014). In mathematics, Skaalvik et al. (2004) controlled for gender, motivation, and verbal ability and also found collinearity between self-concept and achievement.

But for a long time now, self-concept has also been suspected of being a direct predictor of achievement (reciprocal effect). Grigg et al. argued that according to the social cognitive career theory (SCCT), self-efficacy and achievement should be "mutually reinforcing" (2018, p. 75). Often mediated by more sustained efforts or extrinsic motivations, self-concept indeed appears to favour subsequent learning.

Based on their own review of the literature, Grigg et al. argued that previous available evidence is in line with this hypothesis, and were also able to confirm it through a longitudinal panel design in Australia (Grigg et al., 2018). Other longitudinal designs that controlled for (sometimes many) other possible covariables were also able to confirm rather strong bidirectional, reciprocal interaction between achievement and self-concept in Korea (Lee, Lee, \& Bong, 2014), China (Xu, 2018), and Finland (Nuutila et al., 2018). However, the large 
majority of these rather convincing results concerned mathematics, and very few studies focused on science learning.

\section{What About the Relationship Between Interest and Achievement?}

In the research literature, the main references supporting the use of the interest construct [are] to Krapp and Hidi's work, which emphasizes the "relationship (generally positive) between individuals and objects" (2011, p. 94). Renninger and Hidi (2016, p. 8) referred to the general construct of interest as the "psychological state of a person while engaging with some type of content. Interest is thus always in something and this something is usually indicated in the items used to assess it, such as disciplines, objects, or specific situations. Like the construct of attitude, interest is often considered to be composed of affective, cognitive, and behavioural dimensions." (Potvin and Hasni, 2014b).

Researchers recognize at least two major forms of interest (Hidi \& Renninger, 2006). The first is (1) individual interest, which is more durable but more difficult to influence. It is considered a desirable result, one that has some form of resilience and that is presumed to be the product of an accumulation of positive enough circumstantial experiences with an object. There is also the construct of (2) situational interest, which refers to a psychological state that is highly dependent on the immediate context within which it is triggered. When this context disappears (specific teaching practices, teachers, durations or subtopics), chances are that this particular interest will disappear along with it.

Researchers sometimes refer to the first form, and then use agreement items like "Science is interesting" or "Science is important to me." Others refer to the latter (situational) and ask questions like "was this particular activity interesting?" One of the main difficulties often lies in the scope of what is considered a situation. In some instances, such a thing can last a few minutes (Rotgans \& Schmidt, 2011), and for others, an entire semester (Gungor, Eryılmaz, \& Fakıoglu, 2007). Many researchers do not differentiate, or refer to apparently intermediary constructs that appear to be somewhere along a continuum, similar to the one Suzanne Hidi described in her four-phase model of interest (Hidi \& Renninger, 2006).

Interest theory suggests that it can generate achievement by an increase in attention and possibly in engagement (Harackiewicz, Smith, \& Priniski, 2016) and indeed, significant simple correlations are almost always recorded between them (Singh, Granville, \& Dika, 2002).

\section{An Apparent Fragility of the Individual Interest Construct}

However, such correlations seem to weaken when other neighbouring constructs are used as covariables. Unlike self-concept, the predictive power of individual interest does not seem to resist such statistical control. Schneider, Lotz, and Sparfeldt $(2018,31)$, for example, controlled for intelligence and self-concept and found that

[...] regression coefficients of interests in mathematics and German were (substantially) negative in all three grade levels. In contrast to expectations, this means that in the 3-predictor model being less interested in mathematics/reading went along with better reported grades in mathematics/German. Because this relation pattern consistently emerged in (almost) all grade levels as well as in mathematics and German, the occurrence of a statistical artifact (e.g., due to the sample) appears unlikely.

Lee et al. obtained similar results (2014) when they controlled for self-efficacy, grade goals and selfregulation in four different subjects, including science. They found that "individual interest [...] in contrast, was not able to predict their subsequent achievement directly" (Lee et al., 2014, p. 96).

Such results have also been observed for other perceptual variables. For example, when Gagné and St. Père controlled for $I Q$, the effect of motivation on achievement disappeared (2001). Nonetheless, in other designs in which other control variables were used, interest resisted and was a significant predictor of achievement (Kpolovie, Joe, \& Tracy, 2014; Tella, Tella, \& Adeniyi, 2011).

But more recent and sophisticated designs using longitudinal panel protocols and control variables were recently published. All of them raised crucial questions about the predictive power of interest of both types, because none of them recorded sufficiently positive or statistically significant direct links between individual interest and achievement (see Table 1).

Since many of the studies that are presented in Table 1 show nonsignificant or marginal results (right column), they all raise important questions about the possible agency of individual interest on achievement. However, a striking majority of these results were obtained in mathematics learning, and not in science. In addition, these results only raise questions about direct links between interest and achievement, and not possible indirect ones. In other research efforts focusing on science education, indirect or mediated links, for example through "working hard," have indeed been suggested (Patall et al., 2016). Lee also reports such an indirect effect: 
Table 1. A selection of previous longitudinal studies on the effect of interest on achievement

\begin{tabular}{|c|c|c|c|c|}
\hline Reference & Topics & Design & Covariables or control variables & $\begin{array}{l}\text { Interest } \rightarrow \\
\text { achievement }\end{array}$ \\
\hline (Grigg et al., 2018) & Mathematics & $\begin{array}{l}\text { Longitudinal (Two measure } \\
\text { points) }\end{array}$ & $\begin{array}{l}\text { Intentions; self-efficacy; prior } \\
\text { achievement; gender; grade } \\
\text { level }\end{array}$ & n.s. \\
\hline$(\mathrm{Xu}, 2018)$ & Mathematics & $\begin{array}{l}\text { Longitudinal (Two measure } \\
\text { points) }\end{array}$ & Homework, self-concept; effort & n.s. \\
\hline (Nuutila et al., 2018) & Mathematics & $\begin{array}{l}\text { Longitudinal (Three measure } \\
\text { points) }\end{array}$ & $\begin{array}{l}\text { Success expectancy, gender, } \\
\text { task performance }\end{array}$ & n.s. \\
\hline $\begin{array}{l}\text { (Skaalvik \& Skaalvik, } \\
\text { 2004) }\end{array}$ & Mathematics & $\begin{array}{l}\text { Longitudinal (Two measure } \\
\text { points) }\end{array}$ & $\begin{array}{l}\text { Students' goal orientation; self- } \\
\text { concept, self-efficacy, self- } \\
\text { esteem prior grades. }\end{array}$ & n.s. \\
\hline (Denissen et al., 2007) & $\begin{array}{l}\text { English, } \\
\text { mathematics, } \\
\text { science }\end{array}$ & $\begin{array}{l}\text { Longitudinal (Complex set of } \\
\text { data of } 12 \text { grade levels, each } \\
\text { participant followed for } 4 \text { years) }\end{array}$ & $\begin{array}{l}\text { Self-concept of ability, gender; } \\
\text { consciousness; }\end{array}$ & $\begin{array}{l}\text { "modest } \\
\text { coupling" }\end{array}$ \\
\hline $\begin{array}{l}\text { (Ganley \& Lubienski, } \\
\text { 2016) }\end{array}$ & Mathematics & $\begin{array}{l}\text { Longitudinal (Three measure } \\
\text { points) }\end{array}$ & $\begin{array}{l}\text { Confidence; performance; age, } \\
\text { gender }\end{array}$ & n.s. \\
\hline
\end{tabular}

"It was only when individual interest of the students led to better academic self-regulation in the subject that a significant indirect link was made between individual interest and academic achievement." (Lee et al., 2014, p. 96)

It is important to note that many of these research efforts have not always been clear about the type of interest (individual, situational, task-oriented, etc.) that they were measuring. This makes definitive conclusions difficult to produce, since different types can lead to different outcomes.

\section{RESEARCH QUESTIONS}

Considering the questions raised by the mathematics education research literature on the effects of perceptual variables on achievement (and between them), we believe it is important to ask similar questions in the domain of science education. However, in order to come to results that could be as convincing as the best ones we have described above, we believe it is necessary to use a research protocol with the same level of quality, using a longitudinal cross-lagged panel design, and controlling for some of the most often used candidate covariables. We thus ask the following questions:

1. What are the specific and direct effects of selfconcept and individual interest on later achievement in science and technology (and conversely) while controlling for their previous states and for gender?

2. Can self-concept and individual interest be considered as mediators of achievement?

3. What possible indirect links can be observed?

Based on the above described literature and the general framing proposed by Rotgans and Schmidt (2017), we formulate the hypotheses that
- $\left[\mathrm{H}_{1 \mathrm{a}}\right]$ self-concept will predict subsequent achievement and that $\left[\mathrm{H}_{1 \mathrm{~b}}\right]$ achievement will predict subsequent self-concept;

- $\left[\mathrm{H}_{2 \mathrm{a}}\right]$ individual interest will also predict later achievement (and vice versa $\left[\mathrm{H}_{2 b}\right]$ ), and that

- $\left[\mathrm{H}_{3}\right]$ we will record a reciprocal effect between both perceptual constructs.

We have no strong basis for a hypothesis in relation to question No. 3, so we will provide a rather cautious exploratory interpretation at the end. Since all hypotheses are based on the mathematics education literature, it will be interesting to contrast results with science and technology education.

In the end, as stated by Ganley and Lubienski (2016), we believe that

\section{"[u]nderstanding how these constructs are related over time [might] help educators know if they should specifically target students' confidence or interest, if it will naturally follow if we raise students' achievement, or if we need to address confidence, interest and achievement because they are mutually reinforcing." (p. 182)}

\section{METHODS}

\section{Participants}

The analysis includes data from a total of 862 willing participants of first and second years of the secondary course (7 and 8 graders). This level/age was selected in order to represent an important period in the development of interest in S\&T. Indeed, over the course of the first two years of secondary education, individual interest in S\&T has been known to show a certain decline (Potvin and Hasni, 2014a), thus allowing a more thorough analysis of the crucial reasons that lie behind this localised phenomenon. Also, considering a crosssection for which we know there is an important change 
Table 2. Included constructs / variables

\begin{tabular}{|c|c|c|c|c|}
\hline $\begin{array}{l}\text { Name of the latent } \\
\text { construct or variable }\end{array}$ & $\begin{array}{l}\text { Label } \\
\text { used }\end{array}$ & $\begin{array}{l}\text { Number of items } \\
\text { (negative ones } \\
\text { were reversed) }\end{array}$ & & $\begin{array}{l}\text { Used item (translations from French) to infer latent construct, or } \\
\text { source of data }\end{array}$ \\
\hline S\&T self-concept & SC & $12(2)$ & 0.85 & 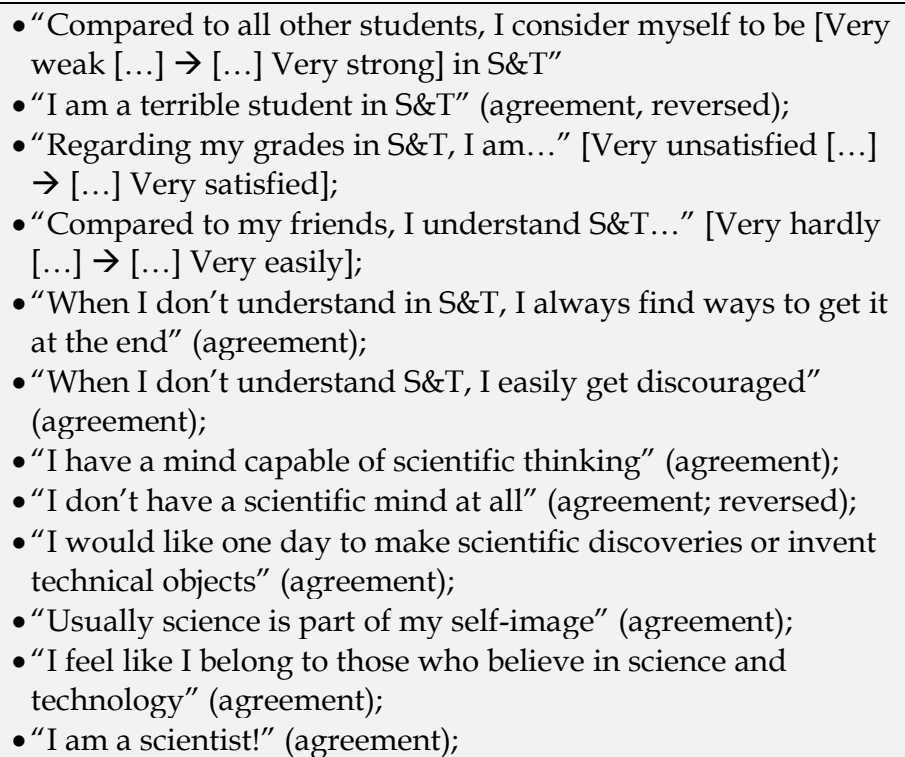 \\
\hline $\begin{array}{l}\text { Interest in school } \\
\text { S\&T }\end{array}$ & INT & $7(3)$ & 0.92 & $\begin{array}{l}\text { - "I look forward to the next S\&T activities" (agreement); } \\
\text { - "S\&T are fun" (agreement); } \\
\text { - "S\&T are boring" (agreement; reversed); } \\
\text { •"School S\&T are interesting" (agreement); } \\
\text { - "What we study in S\&T does not really interest me" } \\
\text { (agreement; reversed); } \\
\text { •"We should spend more time studying S\&T in school" } \\
\text { (agreement); } \\
\text { •"If I had a choice, I wouldn't go to S\&T classes anymore" } \\
\text { (agreement; reversed); }\end{array}$ \\
\hline Achievement & $\mathrm{ACH}$ & $\begin{array}{l}\text { Depend on } \\
\text { classes/schools }\end{array}$ & NA & $\begin{array}{l}\text { Student grades in science and technology, as given by their } \\
\text { teachers }\end{array}$ \\
\hline
\end{tabular}

in interest produces a better chance to significantly associate its variability to other factors. At the start of the data collection, these participants were all beginning their secondary school cycle and were around 11 years old.

They were recruited by educational counsellors who belong to our network in five public secondary schools (each one from a different school board) in the greater Montréal area in the province of Québec, Canada. These schools were considered as typical by their respective school boards, and none of the participants belonged to special science programs. Participants attended science and technology classes that followed the provincial competency-based curriculum and were involved in the project for the entire two-year period.

Written consent was obtained from their parents/guardians in accordance with the conjoint ethical approval form provided by the authors' institution.

\section{Materials}

We used an adapted and validated (Potvin et al., 2018) version of the CRIJEST general questionnaire that was composed of Likert-type items of six levels. All these items were inspired by classic individual interest questionnaires. After questions about identification and gender, questions that followed allowed to infer two latent variables. See Table 2 for information about the latent constructs and the items and information used to infer them.

\section{Protocol}

We exploited the data from the CRIJEST longitudinal study project. This data has already been used to predict perceptual constructs, including the intention to pursue science and technology (Potvin et al., 2018), but has never been used to predict achievement (i.e., as an endogenous variable). In this study, the same questionnaire was administered four times (T1 through T4) during the first two years of the secondary course with the same cohort: Dec. 2014, May 2015, Dec. 2015, and May 2016. These moments were chosen to reflect the state of our considered constructs [a] immediately following the beginning of the secondary course, $[\mathrm{b}]$ as far apart as possible (about 6 months), [c] in line with the moment when report cards were issued, and [d] at the very end of the period under study. 


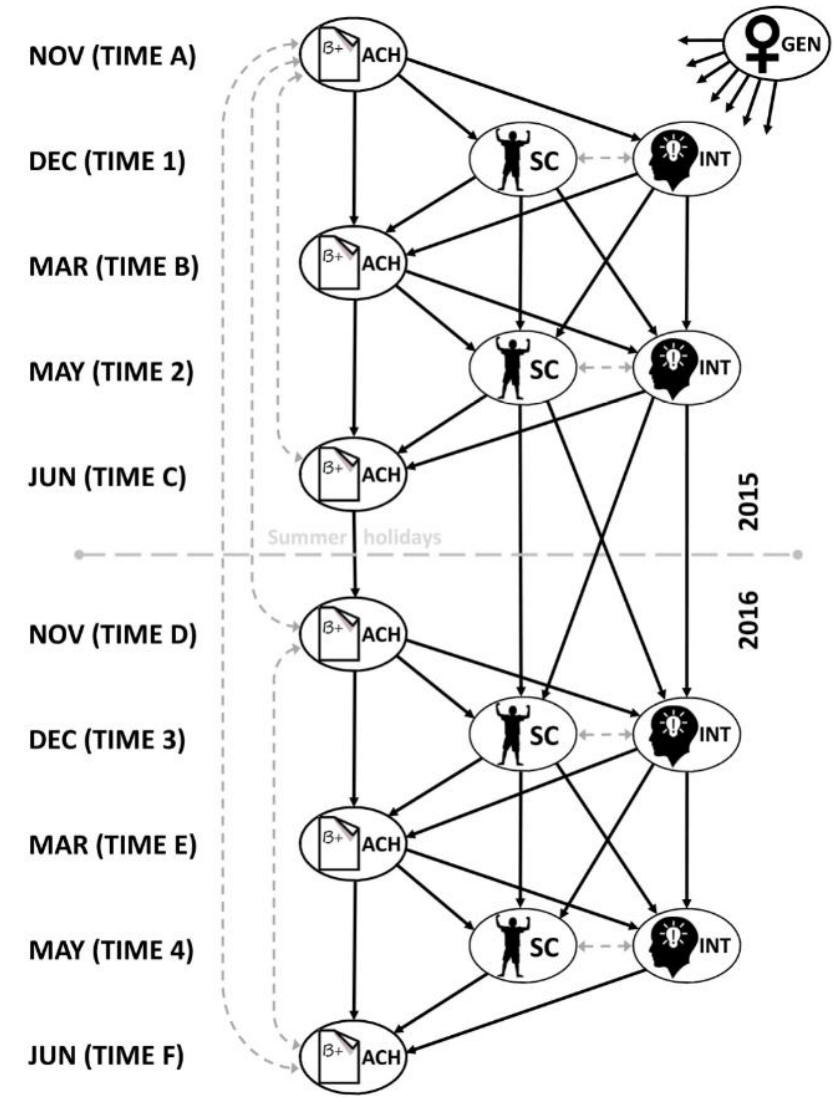

Figure 1 . The initially hypothesized model

Participants filled out the questionnaires in their classrooms, on school time. The experimenter (most of the time pedagogical counselors or in a few cases acquainted with research teachers) first welcomed participants, then reminded them of their rights as such, answered all their questions, read instructions aloud, and allowed them 35 minutes (maximum) to complete the task (questionnaire). About $1.5 \%$ of students could not complete this phase. To ensure anonymity, the completed questionnaires were then collected by the experimenter and sent directly to the university for analysis.

\section{Analysis}

The analysis of the cross-lagged panel design using a structural equation model was conducted with the 7.4 version of the Mplus@ software (Muthén \& Muthén, 1998). In SEM [Structural equation model], unobservable latent variables (constructs or factors, like interest, selfconcept, etc.) "are estimated from observed indicator variables, and the focus is on estimation of the relations among the latent variables" (Wang, 2019, p.1). The method "stems from factor analysis and path analysis" (ibid.) and provides many advantages like "the ability to model multiple dependent variables simultaneously, to test overall model fit [...], and complex and specific hypotheses [...]" (ibid, p.2).

In our research, the tested model (Figure 1) was established on the general principle that the predictive
Table 3. Descriptive statistics for all constructs in the model

\begin{tabular}{lcccc}
\hline $\begin{array}{l}\text { Construct or } \\
\text { variable } \\
\text { (time) }\end{array}$ & Mean & SD & IQR (CV) & Valid (\%) \\
\hline GEN & 0.49 & N.A. & $1(0.34)$ & $862(96.21)$ \\
ACH (A) & 77.60 & 11.93 & $15(0.15)$ & $733(81.81)$ \\
SC (1) & 9.11 & 1.62 & $2.33(0.18)$ & $679(75.78)$ \\
INT (1) & 4.41 & 1.23 & $1.72(0.28)$ & $680(75.89)$ \\
ACH (B) & 77.65 & 11.95 & $16(0.15)$ & $735(82.03)$ \\
SC (2) & 9.10 & 1.76 & $2.5(0.19)$ & $681(76.00)$ \\
INT (2) & 4.03 & 1.37 & $2(0.34)$ & $669(74.67)$ \\
ACH (C) & 74.63 & 12.07 & $16(0.16)$ & $736(82.14)$ \\
ACH (D) & 76.16 & 12.66 & $17.75(0.17)$ & $746(83.26)$ \\
SC (3) & 8.87 & 1.80 & $2.66(0.20)$ & $781(87.17)$ \\
INT (3) & 3.90 & 1.33 & $2(0.34)$ & $773(86.27)$ \\
ACH (E) & 74.54 & 12.14 & $16.50(0.16)$ & $747(83.37)$ \\
SC (4) & 8.67 & 1.88 & $2.67(0.22)$ & $767(85.6)$ \\
INT (4) & 3.73 & 1.32 & $2(0.35)$ & $763(85.16)$ \\
ACH (F) & 73.33 & 12.83 & $17(0.17)$ & $747(83.37)$ \\
\hline
\end{tabular}

power of all three considered latent (self-concept and interest) and observable (grades) variables had to be tested, for each and all four times, by their three most recent states, when available.

In Figure 1, which represents the general hypothesis, regression links appear in black and correlational ones in grey (dotted lines). Correlations between different achievement scores were inserted in the model in order to account (and compensate) for the fact that different objects of knowledge were evaluated each time. The entire model was controlled for gender.

In this figure, the months of December and May (for both 2015 and 2016), when questionnaires were administered, are numbered $(1 \rightarrow 4)$ and the months of November, March and June, when report cards were published, are labelled with letters $(\mathrm{A} \rightarrow \mathrm{F})$.

The usual method for obtaining an acceptable model consists of beginning the modelling with the entire model, and then removing all non-significant links one by one until fit indexes become acceptable (Kline, 2016). However, for consistency, we limited ourselves to either removing all similar links through the entire two-year cycle or not removing them at all. Thus the possible recurrence of significant or non-significant links can be discussed in terms of durability.

Missing data were dealt with using FIML estimation and no candidate pattern for these data could be hypothesized, since missing data were random (vague answers that were sometimes impossible to interpret, etc.).

\section{RESULTS}

\section{Descriptive Statistics}

Table 3 shows the descriptive statistics for all considered constructs. 


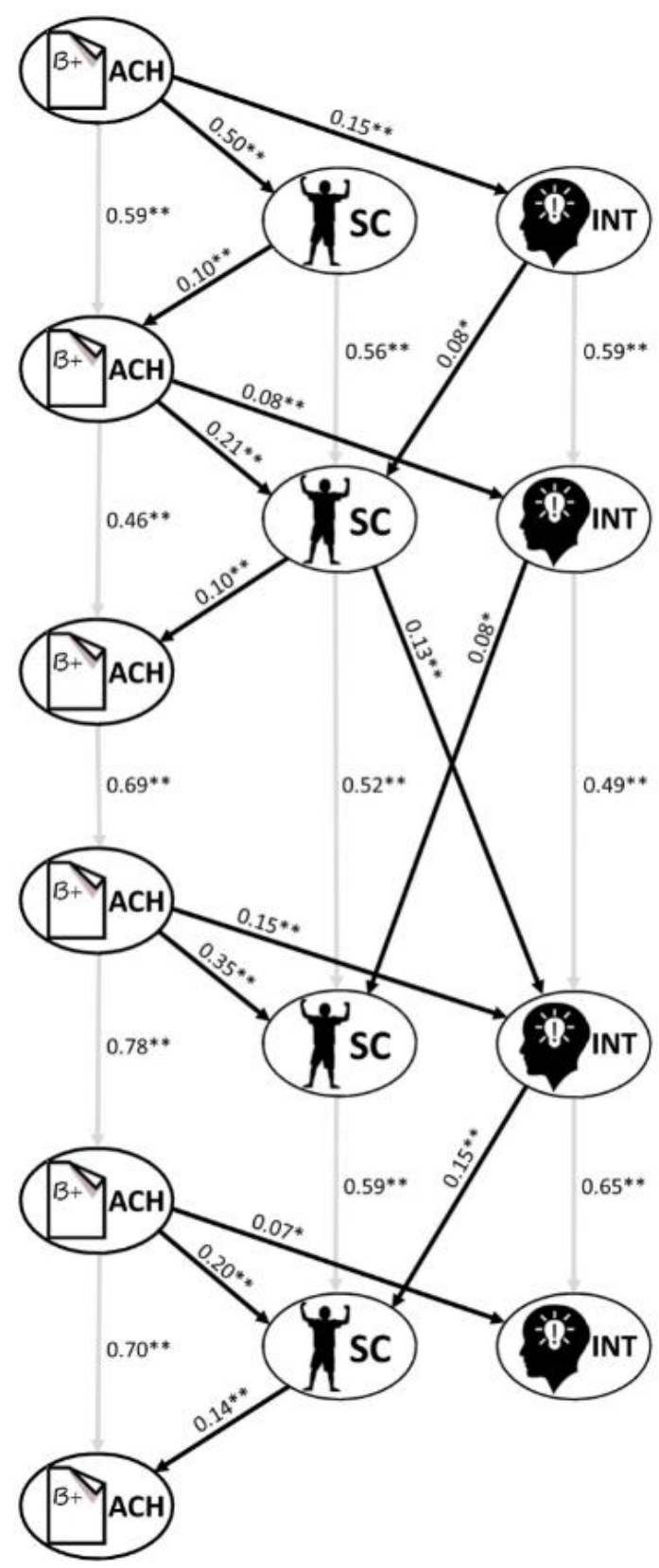

Figure 2. The final model

\section{Results from the Panel Analysis}

The first test of the model revealed that all directional links between individual interest (INT) and immediately subsequent achievement $(\mathrm{ACH})$ were nonsignificant. They were thus removed from the model. The second and final test of the model revealed that all correlational links were significant $(\mathrm{p}<0.001)$ and showed various values, with some of the most interesting between selfconcept (SC) and their concomitant INT (T1 [0.45]; T2 [0.33]; T3 [0.36]; T4 [0.40]). Fit indexes were acceptable for $\mathrm{CFI}=0.95$ (should be $>=0.95$ according to Bentler (1990)) and for SRMR $=0.05$ (should be $<=0.08$ according to Bentler (1995)), and just over the threshold for RMSEA $=0.09$ (should be $<=0.08$ according to Steiger (1990)). We thus believe that the model shows enough robustness to authorize an interpretation, although caution remains important.

Figure 2 shows all surviving standardized beta coefficients in the final model, with levels of significance $\left({ }^{*}<=0.05 ;{ }^{* *}<=0.001\right)$. Stability paths (from one latent construct to its own subsequent state) are in grey and cross-lagged paths are in black. All R-square values are between 38\% (for INT [2]) and 69\% (for ACH [E]), except for SC [1] and INT [1] that have only one predictor (i.e., $\mathrm{ACH}[\mathrm{A}]$ ), suggesting that the model explains a rather fair amount of the observed variance. On all these variables, gender (GEN) proved to be a rather weak predictor, with a large majority of non-significant results $(7 / 10)$ or very weak beta values $(<0.1$ for the remaining regressions).

\section{DISCUSSION}

The final model presented in Figure 2 shows stability paths as well as cross-lagged ones. However, in the following discussion, we will mostly overlook stability paths because of their inability to disconfirm or confirm our hypotheses, and also because of their reduced educational relevance compared to cross-lagged paths, since they might describe steadiness instead of change. The following discussion will be structured around our three research questions.

\section{Research Question No. 1: Self-Concept and Individual Interest as Direct Predictors of Achievement}

Hypothesis 1a (self-concept will predict subsequent achievement). Three times out of four (except at T3), selfconcept showed its direct predictive power on subsequent achievement with $B$ values of 0.10 (T1), 0.10 (T2) and 0.14 (T4). Thus, it appears reasonable to affirm that our results seem to support other studies that argue that a stronger self-concept predisposes students to better academic performance, possibly through an increase of sustained effort and work that eventually pays off on exams. This result seems to be strong enough to resist statistical control for interest, gender and, most of all, of previous achievement, which remains the first predictor for all iterations.

Hypothesis 2a (individual interest will also predict later achievement). At no point in our final model was individual interest in school SET a significant direct predictor of later achievement. This rather surprising result must, however, be interpreted with caution, since an absence of significant proof cannot be conclusively interpreted as a proof of absence. Nonetheless, we believe that the honesty of our effort (using a validated questionnaire, controlling for relevant variables, involving several hundred participants, etc.) suggests that this absence may be of concern, especially when remembering that other researchers have found the same pattern in mathematics (see Table 1). Indeed, it could mean that the hypothesis that individual interest 
is presumed to generate more engagement and attention and, in turn, better performance, might remain unconfirmed.

And indeed, this "standard hypothesis" (p. 351) has recently been challenged by Rotgans and Schmidt (2017). Even though they present it as "[...] so intuitively selfevident and so ingrained in the way we think about the influential role of interest in education, that educators and educational researchers seem to have forgotten to consider alternatives" (p. 350), these authors provide rather strong experimental evidence that it can hardly be confirmed. Their results confront many of the arguments provided by Hidi and her followers and this squabble has even become explicit in published articles (Schmidt \& Rotgans, 2017).

We believe that while our results also challenge the standard hypothesis, it remains possible that individual interest might still affect performance, but maybe indirectly, through other constructs not measured here. However, if that was the case, then we probably should have seen a direct, although weak effect.

\section{Research Question No. 2: Self-Concept and Individual Interest as Possible Mediators of Achievement}

Hypothesis 1b (achievement will predict subsequent self-concept). Since $\left[\mathrm{H}_{1 \mathrm{a}}\right]$ is confirmed, we can direct our attention to $\left[\mathrm{H}_{1 \mathrm{~b}}\right]$ to see if achievement feeds subsequent self-concept. Without surprise, it seems to do so at every iteration (T1 through T4, with rather strong $B$ s of $0.50 ; 0.21 ; 0.35$; and 0.20$)$, suggesting at the end that self-concept acts as a mediator of achievement, both these constructs nourishing each other, with a dominance of achievement toward selfconcept. As argued before, this result is rather unsurprising because it had also been suggested by Grigg et al. through the social cognitive career theory (SCCT) that they were mutually reinforcing (2018), but also because it seems obvious that grades are the most important source of self-evaluation. The form in which these grades are usually provided (right next to the mean of the class) also possibly contributes to strengthening a comparative construct (better/worse than other students of the class) such as our self-concept.

Hypothesis $\mathbf{2 b}$ (achievement will predict individual interest). However, since $\left[\mathrm{H}_{2 \mathrm{a}}\right]$ has not been confirmed, it is not possible for us to argue that individual interest acts as a mediator of achievement. We can nevertheless confirm $\left[\mathrm{H}_{2 \mathrm{~b}}\right]$, as achievement records significant albeit weak predictive power over subsequent individual interest, with $B$ values of $0.15 ; 0.08 ; 0.15$; and 0.07 . This result suggests that getting good grades does influence individual interest positively. This result is not negligible since the role of interest on the pursuit of studies and career choice could remain important. However, since our results do not show any reciprocal effect, more research is needed to confirm that interest is not just a "shadow variable" but also a factor in other ways.

\section{Research Question No. 3: Interaction Between Self- Concept and Interest}

We do not believe our data allows us to conclude that there are strong reciprocal effects between individual interest and self-concept (which is $\left[\mathrm{H}_{3}\right]$ ). However, on a single occasion (T2 $\rightarrow \mathrm{T} 3$ ) self-concept predicted individual interest $(B=0.13)$. More interestingly, at every possible iteration, interest allowed a prediction of subsequent self-concept with, however, rather weak values $(0.08 ; 0.08$; and 0.15$)$. We can thus conclude that there is a possible indirect effect of individual interest on achievement through self-concept. This interesting result reconfirms that interest is clearly subordinated to selfconcept in the prediction of achievement, but revives the possibility that it still could be more than just a shadow variable. It could indeed suggest that a high interest can help convince students (legitimately or not) of their selfworth on the considered topic, and thus still have positive indirect effects on grades. However, the very weak regression values compel caution in this matter. Also, we have to remind the reader that regression tests do not only work in positive directions, meaning that a weak interest could do the opposite, i.e., have a negative indirect effect on self-concept and, by domino effect, on achievement.

\section{Other Possible Interpretations}

Aside from the above discussed and rather dry interpretation that interest alone does not predict achievement, other, more general hypotheses can be provided to try to explain the "negative" result that $\mathrm{H}_{2 \mathrm{a}}$ remains unconfirmed.

The first one refers to the particular nature of academic activities that might currently be used in our tested schools to educate children in science and technology at those particular levels (grades 7-8). Indeed, it appears possible that these scientific and technological activities are so remote from the realities of evaluation (tests and exams) or of real scientific activity that the interest they may trigger has no measurable effect on achievement. In other words, schools might be so focused on grades that most of everything else is subordinated to them, even to the point of being disconnected from S\&T content and methods as they exist in the out-of-school scientific community. Similar hypotheses about an important rupture or misalignment between content and evaluation have been suggested before. Didacticians like Astolfi (1998) and sociologists like Perrenoud (2004) have described the regrettable and widespread pedagogical culture of "métier de l'élève" (student's job) which essentially reduces learning activities to answering the teaching adult's questions and other solicitations in such a way as to obtain their 
minimal and sufficient approval, even when those answers might be truncated and poor in actual content. It can be supposed that in the transition between primary and secondary education (like our participants), students are progressively more acquainted with such a culture and rapidly conform to it, that is, if they were not already acquainted with it as a result of their elementary education.

Another explanation focuses on the possible shortcomings of the chosen construct, its definition and/or the means that are deployed to assess it (items, questionnaires). It is not impossible, indeed, that the construct of individual interest was measured too loosely and/or was subject to important social desirability or other similar biases. Clearly, interest in SET is usually something that is socially "positively viewed", and if it is tested without putting subjects' perceptions under tension with other considerations or references, these participants might produce answers without sufficient seriousness or introspection. In other words, they could produce answers that are inspired by very broad impressions of what the object does or should inspire, in a low-stakes context, thus without vigilance or foreseen decisive consequences. Such a problem has already been described in a previous meta-synthesis in which it was regretted that "perception questionnaires are not 'tasks' in the strict sense of the term. The concept of a 'task' suggests difficulty, or a challenge" (Potvin and Hasni, $2014 b$ ). In the same line of thought, we would prefer to have questionnaires that put the interest construct "to the test," instead of merely testing its presence. In a Popperian perspective, it indeed appears preferable to have propositions that have resisted refutations (Popper, 1995) instead of propositions that have merely been positively evidenced.

For instance, while taking into account both the subject and the object as well as the link that exists (or not) between them, the construct of interest is sometimes measured with items that partly or completely conceal the subject. An agreement item like "I think science is interesting" could unfortunately be interpreted by participants as "I believe that science is usually interesting for ordinary people" instead of as "science interests me." In such cases, an objective judgment about the topic is produced, but without strongly referring to one's self, or to one's feelings, and thus possibly creating the observed misalignment between the initially hypothesized construct and personal academic performances.

Such an example leads us to the possible conclusion that, at least as it is usually measured, the construct of individual interest might not have the teeth we suspected, and if it still can be a worthy indicative variable, its own predictive power might not be strong enough to allow confirmation of hypotheses about performance. In comparison, the construct of self-concept might appear to be more robust, especially since it is often measured in relation to more concrete references like other students' academic performances, with items like "in S\&T, I am [stronger $\rightarrow$ weaker] than my classmates." Such an item almost necessarily compels introspection that is more thorough and contains a strong and "objective" (i.e., quantified) reference (class's average performance or grades) which, furthermore, is updated on a continuous basis and even sometimes with public display. The construct of interest does not have all that. This might be why it collapses when self-concept is concomitantly controlled.

Finally, a third explanation for the lack of positive effect of individual interest on achievement brings us to the breadth of the object that items usually refer to. Indeed, "Science and technology" encompasses a very large and diverse set of disciplines, subdisciplines, subject-matter objects and activities, and it is rather difficult to be certain of what we precisely refer to when we invoke this general field. It is even more difficult to be certain about what participants refer to when they answer our items, even when their experiential scope might be limited to school activities. Thus it is possible that our items simply induce too much noise in the process to allow detection of any predictive power. However, since S\&T directed self-concept also refers to the broad field of "school science and technology" and still records an effect on achievement, it might be limited, even if grades might reduce this complexity to a single performance value.

These three hypotheses described above might not be sufficient to explain the conjectured inability of interest to predict performances, but they both might be at least part of the problem. Indeed, even if statistical tests appear to disqualify interest as a credible factor, it still appears counterintuitive to deny it any role in subsequent learning, and eventually on achievement. Thus we believe that it should at least benefit from genuine rescue attempts before being thrown away.

\section{Possible Implications for Research and Practice}

Therefore, in research efforts that strive to assess or isolate the construct of interest, its variations and agency, there are a few things that could be suggested. First, it could be beneficial to ensure that items used to infer interest all clearly and explicitly refer to the participant, his/her feelings, understandings and intentions, and not only to the impersonal object of interest per se. "This interests $\mathrm{me}^{\prime \prime}$ is indeed different from "this is interesting".

Second, it could be more productive to incorporate not only the benefits that are provided by proximity or interaction with an object, but also its conjectured or established costs. In previous research efforts, the predictive power of perceived difficulty (or its opposite, ease) was evaluated and found to be highly predictive of many subsequent perceptual constructs, including self- 
concept (Potvin et al., 2018). Thus the "perceived difficulty" variable could be considered here as a factor that limits interest, and thus as part of it. And it might not be unreasonable to say that a person could like science while also believing that science might not necessarily be worth the effort required to succeed at it. This suggestion, however, puts into question the legitimate destination of the "perceived difficulty" dimension of perception, because from time to time, it has mostly been seen to be included in "self-efficacy" variables. However, we believe that its place in the interest construct remains defendable, because if someone believes learning science requires too much effort, then it might appear to not be as much in his or her interest to be in contact with it.

Third, narrowing the scope of the targeted object that a subject interacts with to simpler, shorter or more precise things or activities might help to reduce the noise that can sometimes come with its measurement. For example, some people are often fonder of biology than of physics (or vice versa), and some are more inclined to appreciate science than technology (or vice versa). Having items that refer simultaneously to all these things (i.e., "S\&T learning" or, as is sometimes the case, "STEM" (science, technology, engineering, mathematics)) might confuse or puzzle participants, disperse their answers, constrain them to provide their overall impressions, or make them fall back on social desirability in order to provide a credible answer. The targeted object of interest could also target shorter activities, helping participants focus on less complex events. However, by doing so, we could be putting at risk the distinction between individual and situational interest that is usually considered as fundamental.

Fourth, researchers could favour the use of items that constrain subjects to express their perceptions in comparison with external points of reference. For example, "I like science" might be more naïve and less introspectively constraining than "I like science more than I like math" or than "I like science more than I like other school topics." To allow better inter-subject comparisons, such basis could be selected because they are more widely socially shared by most, or by all.

Thus, we suggest that further research efforts consider and use a more robust and less naïve interest construct in their designs. In our view, such a construct should be assessed in relation with more precise surroundings constructs, objects, phenomena or activities than it is the case in many current and past research efforts. We suggest such a relativity because (1) interest would essentially be related to the self and thus would be more egocentric (i.e., avoiding allocentrism); (2) it would compute a "cost/benefit" evaluation rather than a mere positive and absolute evaluation of the supposed, felt or true benefits in all of interest's classical dimensions (affective, cognitive, behavioural); (3) it would be expressed in relation to a more precise object or type of activity and (4) it would be put in explicit comparison with other widespread related activities or topics.

We believe that such ingredients for a relative individual interest variable could be best suited for a construct that might have predictive power on educationally relevant and related-to-curriculum outcomes. Instead of asking themselves, "Am I interested in learning [e.g.] biology?" participants would ask themselves, "What's my interest in learning biology?" Of course, such a concept that concentrates on personal benefits would then flirt with-and possibly overlap with - the construct of motivation. But it might also feel rather uncalled for to completely disqualify benefits or desires (Odudukudu, 2019) from the assessment of interest, especially as it was originally defined as focused on the advantages that considered object provide (Dewey, 1913).

For the purposes of educational practice, we believe our results reiterate the importance of encouraging students to perform and valorize their persons as learners as well as their efforts. Keeping students convinced that they are capable of overcoming difficulties and of taking up the different challenges that school science imposes seems to remain an important causal factor in academic success. No discovery here, but a possible reconfirmation.

However, our results also suggest that individual interest might better express itself in special circumstances as opposed to a robust trait that educators should count on when learning is the objective. Thus these results should help convince teachers that individual interest is a fragile thing, and might be more easily dependent on the intimacy of the class, between a teacher and a learner (and/or between learners) in very specific learning situations, at all instants. Thus all teaching situations and contexts, big or small, might deserve attention.

\section{CONCLUSION}

This study makes a contribution by confirming that the agency of interest in achievement can hardly be recorded, at least as it is generally measured, when controlling for neighbouring perceptual constructs such as self-concept. This research seems to align with other similar results that were obtained in recent math education studies (Denissen et al., 2007; Ganley \& Lubienski, 2016; Grigg et al., 2018; Nuutila et al., 2018; Skaalvik \& Skaalvik, 2004; Xu, 2018), suggesting a certain transdisciplinary conformity of the constructs considered.

Limitations of this research concern the usual causality problem, inherent to all regression statistical tests. However, in longitudinal designs, even if causalities cannot be absolutely secured, we can nonetheless bring causal arguments to the discussion, 
based on multiple anteriorities. Another limitation is, of course, inherent to the items used. For this matter, we have proposed possible solutions based on a more relative version of individual interest. However, these solutions have not yet been tested, and their value cannot be confirmed. We therefore intend to pursue efforts in this direction.

Last, we should keep in mind that our research was conducted with secondary school students (7-8th graders) and thus we do not know how younger or older students would react. For example, at the end of the secondary course, when students are obliged to make their first serious commitments toward the topic/subject that they will eventually pursue in post-secondary, it is reasonable to believe that perceptions might have very different effects.

Our results, however, support the hypothesis of a reciprocal relation between self-concept and achievement, suggesting that encouragements and (thus) positive self-evaluation play an important role in achievement. This result, however, can also elicit concern, because if good grades generate confidence and confidence generates good grades, we can then believe that school acts more as a constant engine of discrimination between children than as a gap closer. Thus the selective aspects of the evaluation process could be questioned, as well as its capability to indeed evaluate the considered topic (scientific and technological concepts and competencies), while avoiding the assessment of other confounding variables, like reading abilities, mere memorization, procedural capabilities, correct-answer algorithm application, confidence, examination stress, etc.

In the end, we believe that much more research has to be conducted in order to study the causal relations that perceptual constructs have with educationally relevant outcomes, and that such a research program should remain vigilant about its implicit assumptions and the quality of the material it uses.

\section{Compliance with Ethical Standards}

All procedures performed in studies involving human participants were in accordance with the ethical standards of the institutional committee of the Université de Sherbrooke and with the 1964 Helsinki declaration and its later amendments or comparable ethical standards.

\section{ACKNOWLEDGEMENTS}

Special thanks to the following school boards for their financial and organizational help with this project: Commissions scolaires de Montréal, Rivière-du-Nord, des Hautes-Rivières, des Grandes-Seigneuries and Marie-Victorin. We would also like to thank David Covino (CSDGS), Bénédicte Boissard (CSRDN), Maria Naciri (CDMV), Jean-François Michaud (CSHR), Geneviève Morin (CSDM), Françoise Plante (CSDM) and
Daniel Lytwynuk (CSDM) for their help collecting data, and all the teachers who accepted to devote class time to this project. Thank you also to the participants for their honesty and their time, to Jill Vandermeerschen for her insight with the data analysis, and to Mohamed Amine Mahhou for his help with data entry.

\section{REFERENCES}

Astolfi, J.-P. (1998). L'école pour apprendre [Learning happens in school]. Paris: ESF Éditeur.

Bentler, P. M. (1990). Comparative fit indexes in structural models. Psychological Bulletin, 107(2), 238246. https:/ / doi.org/10.1037/0033-2909.107.2.238

Bentler, P. M. (1995). Eqs structural equations program manual. Encion, CA: Multivariate Software.

Brookover, W. B., Thomas, S., \& Paterson, A. (1964). Selfconcept of ability and school achievement. Sociology of Education, 37(3), 271-278. https://doi.org/ $10.2307 / 2111958$

Cavas, P. (2011). Factors affecting the motivation of turkish primary students for science learning. Science Education International, 22(1), 31-42.

Denissen, J. J. A., Zarrett, N. R., \& Eccles, J. S. (2007). I like to do it, I'm able, and I know I am: longitudinal couplings between domain-specific achievement, self-concept, and interest. Child development, 78(2), 430-447. https:/ / doi.org/10.1111/j.1467-8624.2007. 01007.x

Dewey, J. (1913). Interest and effort in education. Boston, MA, US: Houghton, Mifflin and Company.

Gagné, F., \& St Père, F. (2001). When IQ is controlled, does motivation still predict achievement? Intelligence, 30(1), 71-100. https:/ / doi.org/10.1016/ S0160-2896(01)00068-X

Ganley, C., M., \& Lubienski, S. T. (2016). Mathematics confidence, interest, and performance: Examining gender patterns and reciprocal relations. Learning and Individual Differences, 47(April), 182-194. https://doi.org/10.1016/j.lindif.2016.01.002

George, R. (2006). A cross-domain analysis of change in students' attitudes toward science and attitudes about the utility of science. International Journal of Science Education, 28(6), 571-589.

Grigg, S., Perera, H. N., McIlveen, P., \& Svetleff, Z. (2018). Relations among math self efficacy, interest, intentions, and achievement: A social cognitive perspective. Contemporary Educational Psychology, 53, 73-86. https://doi.org/10.1016/j.cedpsych. 2018.01.007

Gungor, A., Eryılmaz, A., \& Fakıoglu, T. (2007). The relationship of freshmen's physics achievement and their related affective characteristics. Journal of Research in Science Teaching, 44(8), 1036-1056. https:/ / doi.org/10.1002/tea.20200 
Harackiewicz, J. M., Smith, J. L., \& Priniski, S. J. (2016). Interest matters: The importance of promoting interest in education. Policy Insights from the Behavioral and Brain Sciences, 3(2), 220-227. https:// doi.org/10.1177/2372732216655542

Hidi, S., \& Renninger, K. A. (2006). The four-phase model of interest development. Educational Psychologist, 41(2), 111-127.

Honicke, T., \& Broadbent, J. (2016). The influence of academic self-efficacy on academic performance: A systematic review. Educational Research Review, 17, 63-84.

https:/ / doi.org/10.1016/j.edurev.2015.11.002

Kline, R. B. (2016). Principles and practice of structural equation modeling (4th edition). New-York, London: Guilford publications.

Kpolovie, P. J., Joe, A. I., \& Tracy, O. (2014). Academic achievement prediction: role of interest in learning and attitude towards school. International Journal of Humanities Social Sciences and Education, 1(11), 73100.

Krapp, A., \& Prenzel, M. (2011). Research on interest in science: Theories, methods, and findings. International Journal of Science Education, 33(1), 2750.

Larson, L. M., Stephen, A., Bonitz, V. S., \& Wu, T.-F. (2014). Predicting science achievement in india: Role of gender, self-efficacy, interests, and effort. Journal of Career Assessment, 22(1), 89-101. https:// doi.org/10.1177/1069072713487975

Lee, W., Lee, M.-J., \& Bong, M. (2014). Testing interest and self-efficacy as predictors of academic selfregulation and achievement. Contemporary Educational Psychology, 39(2), 86-99. https:/ / doi.org /10.1016/j.cedpsych.2014.02.002

Leflot, G., Onghena, P., \& Colpin, H. (2010). Teacherchild interactions: Relations with children's selfconcept in second grade. Infant and Child Development, 19(4), 385-405. https://doi.org/ 10.1002/icd.672

Lent, R. W., Brown, S. D., \& Hackett, G. (1994). Toward a unifying social cognitive theory of career and academic interest, choice, and performance. Journal of Vocational Behavior, 45(1), 79-122. https://doi.org/10.1006/jvbe.1994.1027

Lent, R. W., Larkin, K. C., \& Brown, S. D. (1989). Relation of self-efficacy to inventoried vocational interests. Journal of Vocational Behavior, 34(3), 279-288. https:/ / doi.org/10.1016/0001-8791(89)90020-1

Muthén, L., \& Muthén, B. (1998). Mplus user's guide (7th $e d n)$. Los Angeles, CA, 2012: Muthén \& Muthén.

Nuutila, K., Tuominen, H., Tapola, A., Vainikainen, M.P., \& Niemivirta, M. (2018). Consistency, longitudinal stability, and predictions of elementary school students' task interest, success expectancy, and performance in mathematics. Learning and Instruction, 56, 73-83. https:/ / doi.org/ 10.1016/j.learninstruc.2018.04.003

Odudukudu, M. (2019). Pure and objective thinking: interest and desire. SAGE Open, 9(2), 2158244019844086.

https:/ / doi.org/10.1177/2158244019844086

OECD [Hemmo, V., \& Love, P.] (2008). Encouraging student interest in science and technology studies. OECD Publishing.

Patall, E. A., Vasquez, A. C., Steingut, R. R., Trimble, S. S., \& Pituch, K. A. (2016). Daily interest, engagement, and autonomy support in the high school science classroom. Contemporary Educational Psychology, 46, 180-194.

Perrenoud, P. (2004). Métier d'élève et sens du travail scolaire [Students' role and sense of school work]. Paris: ESF-Éditeur.

Popper, K. R. (1995). La logique de la découverte scientifique [The logic of scientific discovery]. Paris: Éditions Payot.

Potvin, P., \& Hasni, A. (2014a). Analysis of the decline in interest towards school science and technology from grades 5 through 11. Journal of Science Education and Technology, 23(6), 784-802. https:/ / doi.org/10.1007/s10956-014-9512-x

Potvin, P., \& Hasni, A. (2014b). Interest, motivation and attitude towards science and technology at K-12 levels: a systematic review of 12 years of educational research. Studies in Science Education, 50(1), 85-129, https://doi.org/10.1080/03057267. 2014.881626

Potvin, P., Hasni, A., Sy, O., \& Riopel, M. (2020). Two Crucial Years of Science and Technology Schooling: A Longitudinal Study of the Major Influences on and Interactions Between Self-Concept, Interest, and the Intention to Pursue S\&T. Research in Science Education, 50, 1739-1761. https://doi.org/10.1007/ s11165-018-9751-6

Reid, N., \& Skryabina, E. A. (2002). Attitudes towards physics. Research in Science and Technological Education, 20(1), 67-81.

Renninger, K. A., \& Hidi, S. E. (2016). The Power of Interest for Motivation and Engagement. New-York: Routledge.

Rotgans, J. I., \& Schmidt, H. G. (2011). The role of teachers in facilitating situational interest in an active-learning classroom. Teaching and Teacher Education, 27(1), 37-42. https://doi.org/10.1016/ j.tate.2010.06.025

Rotgans, J. I., \& Schmidt, H. G. (2017). The relation between individual interest and knowledge 
acquisition. British Educational Research Journal, 43(2), 350-371. https:/ / doi.org/10.1002/ berj.3268

Schiefele, U., Krapp, A., \& Winteler, A. (1992). Interest as a predictor of academic achievement: A metaanalysis of research The role of interest in learning and development. (pp. 183-212). Hillsdale, NJ, US: Lawrence Erlbaum Associates, Inc.

Schmidt, H. G., \& Rotgans, J. I. (2017). Like it or not: Individual interest is not a cause but a consequence of learning. Rejoinder to Hidi and Renninger (2017). British Educational Research Journal, 43(6), 1266-1268. https:// doi.org/10.1002/ berj.3307

Singh, K., Granville, M., \& Dika, S. (2002). Mathematics and science achievement: effects of motivation, interest, and academic engagement. Journal of Educational Research, 95(6), 323-332.

Skaalvik, E. M., \& Skaalvik, S. (2004). Self-concept and self-efficacy: A test of the internal/external frame of reference model and predictions of subsequent motivation and achievement. Psychological Reports, 95(3_suppl), 1187-1202. https://doi.org/10.2466/ pr0.95.3f.1187-1202

Steiger, J. H. (1990). Structural model evaluation and modification: An interval estimation approach. Multivariate Behavioral Research, 25(2), 173-180. https://doi.org/10.1207/s15327906mbr2502_4

Tella, A., Tella, A., \& Adeniyi, S. O. (2011). Locus of control, interest in schooling and self-efficacy as predictors of academic achievement among junior secondary school students in Osun State, Nigeria. New Horizons in Education, 59(1), 25-37.

Wang, J., \& Wang, X. (2019). Structural equation modeling: Applications using Mplus. John Wiley \& Sons.

Xu, J. (2018). Reciprocal effects of homework selfconcept, interest, effort, and math achievement. Contemporary Educational Psychology, 55, 42-52. https://doi.org/10.1016/j.cedpsych.2018.09.002

\section{http://www.ejmste.com}

